\title{
Erratum to: Innovation in High-Technology SMMEs: The Case of the New Media Sector in Cape Town
}

\author{
Irma Booyens • Neo Molotja • Madalitso Z. Phiri
}

Published online: 22 March 2013

(C) Springer Science+Business Media Dordrecht 2013

\section{Erratum to: Urban Forum}

\section{DOI 10.1007/s12132-012-9168-7}

In the original publication of this article, there was a mistake in figure 3 . The correct version is presented here.

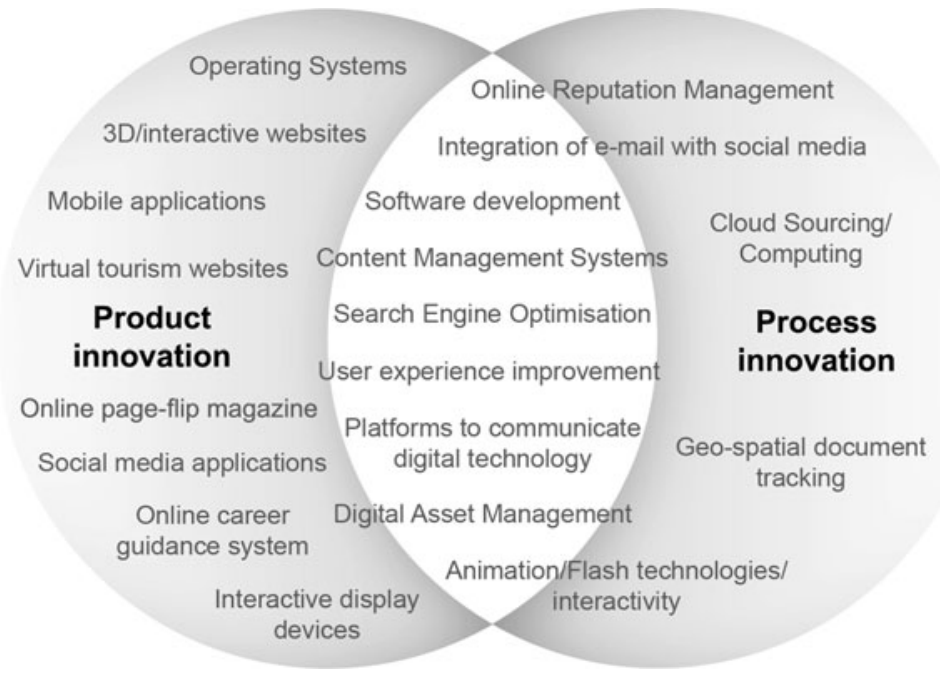

The online version of the original article can be found at http://dx.doi.org/10.1007/s12132-012-9168-7.

I. Booyens $(\bowtie)$

Department of Geography, Environmental Management and Energy Studies, University of Johannesburg, PO Box 524, Auckland Park 2006, South Africa e-mail: Irma.booyens@gmail.com 